\title{
Knowledge Level About Insects and Mites of Health School Students
}

\author{
Nil Bagriacik ${ }^{1}$, Cigdem Samanci Tekin ${ }^{2}$ \\ ${ }^{1}$ Niğde Ömer Halisdemir University Faculty of Arts and Sciences, Biology Department, Niğde, Turkey \\ ${ }^{2}$ Niğde Ömer Halisdemir University, Faculty of Medicine, Internal Medical Sciences, Department of Public Health, Niğde, Turkey
}

Correspondence Author: Cigdem Samanci Tekin

E-mail: cigdemstekin@hotmail.com

Received: $17.04 .2020 \quad$ Accepted: 22.05 .2021

\begin{abstract}
Objective: Today, diseases transmitted by insects and mites still remain an important public health problem. Therefore, the training received by health personnel and their experiences on this topic is important. This study was conducted to determine the knowledge and experiences of students, who were health personnel candidates, on insects and mites likely to be encountered in hospitals or on patients

Methods: This study is cross-sectional. No sample selection was made and 1st - and 4th-grade students in midwifery and nursing departments constituted the universe. Independent-samples t-tests compared knowledge to identify differences by students ' experiences and education about insects and mites, $\chi 2$ tests compared frequency of correct knowledge answers according to experiences and education about insects and mites.

Results: The participants stated that, in their daily lives, they mostly encountered cockroaches (77.9\%) in their environment and lice (52.5\%) on their bodies. In this study, the prominent finding was that both experiences and education were important in getting information on insects and mites. Students' ratio of thinking that they had sufficient knowledge on insects and mites, the ratio of recognizing insects and mites given in images, the mean scores of correct answers given to the propositions on insects and mites, and the knowledge of struggling methods were low.

Conclusion: Today's changing environmental conditions have increased the risk of confronting epidemics related to insects and mites at any time. Therefore, it is highly important for health personnel, who are actively involved in epidemics and who consult the community, to receive effective training on insects and mites during the university period.
\end{abstract}

Keywords: Insect, Mite, Knowledge Level, Nursing Education, Public Health

\section{INTRODUCTION}

Many diseases are carried and transmitted by arthropods (Arthropoda), especially insects (Insecta), mites and ticks (Acari) in tropical and subtropical regions of the world. These organisms operate as biological or mechanical vectors for the spread of human-to-human and animal-tohuman transmitted diseases, parasites, and their eggs on earth (1). At the same time, the developmental stages of insect populations (age composition of insect populations) constitute an epidemiological risk (2). Diptera (mosquitoes, black flies, sand flies, blowflies, flesh flies, horse flies, deer flies, stable flies, and house flies), Hemiptera (bed bugs and assassin bugs), Siphonaptera (fleas), Phthiraptera (sucking lice) and Dictyoptera (cockroaches) are most important insect groups for human health (3).

Especially, hospitals are suitable premises for harboring and spreading of many pathogens. Cockroaches (Insecta: Dictyoptera) have a very important role in the spread of nosocomial infections and drug-resistant bacteria in hospitals (4). 82 pathogenic bacteria were isolated from the flies (Insecta: Diptera) collected from hospitals in the UK and 68 strains of them were found to be resistant to antibiotics (5). Cockroaches are present in many areas that humans use in their daily lives such as houses, restaurants, hotels, malls, residences (6). The production of allergens triggering asthma and rhinitis negatively affects human health by causing the transport of enteric pathogens and psychological stress. Urban populations with low-income are the most powerful risk groups for susceptibility to cockroach allergens and the development of asthma $(7,8)$.

Pediculosis is a parasitic disease caused by human lice (Insecta: Phthiraptera). It may originate from the head, clothes, and pubic lice depending on the etiological factor. Head pediculosis is epidemic worldwide (9). The prevalence of pediculosis is variable depending on socioeconomic status, population density, and hygiene rules $(10,11)$. 
Fleas (Insecta: Siphonaptera) are able to transmit agents of infectious diseases in humans and animals. Flea-borne infections are common worldwide and may have a high incidence (12). These zoonotic agents are transmitted to humans mainly through bites or exposure of feces to itchy bite lesions (13).

Bedbug (Insecta: Hemiptera) is a nocturnal, flightless ectoparasite that preferably feeds on human blood (14). The bite of a bedbug causes physical and psychological problems such as itching, rashes, allergies, insomnia, anxiety; moreover, bedbugs create serious economic concerns and quality of life problems for households $(15,16)$.

Scabies is a skin disease caused by Sarcoptes scabiei var. hominis (Arachnida: Acari) in humans. It is commonly seen in the world and affects humans of all races and social statuses. It is transmitted by close contact and can lead to rapid epidemics in families, dormitories, kindergartens, and nursing homes (17). Ticks are considered to be the second among the vectors of disease-causing factors in humans. It is reported that there are more than 100,000 diseases caused by tick-borne pathogens (18). Therefore, they are medically important ectoparasites. In the world and in Turkey, mite - and insect-borne diseases remains to be a major public health problem. In Turkey, currently, there are 3,649,750 Syrian refugees by 2019 (19) and the increase in infectious diseases is remarkable (20). Refugees may carry new health problems to migration areas where these problems have not been there before. Therefore, it is highly important to give primary preventive health services to immigrants (21).

After the realization of family practice system in Turkey, mostly nurses and midwives have been started to be assigned in family health centers (22). The lack of environmental health personnel in family health centers necessitates midwives and nurses to have knowledge of all aspects of health, including environmental health services. It is important for midwives and nurses to have knowledge and experience about insects and mites as health consultants. Health workers should recognize insects and mites in order to protect themselves and their environment have information on the diseases and preventive methods. Experiences and education ensure the acquisition of this knowledge.

The most common insects and mites that are scabies, louse, flea, tick, bedbug, and cockroach were involved in this study. The aim was to determine the knowledge levels of students studying in midwifery and nursing departments.

\section{METHODS}

\subsection{Participants}

The cross-sectional descriptive study design was employed. 281 1st - and 4th-grade students in midwifery and nursing departments participated in this research. No sample selection was made, and it was aimed to reach the whole universe. The rate of participation was $93.3 \%$.

\subsection{Measures}

A questionnaire was prepared by the researchers by reviewing the literature and it was applied to the participants. The questionnaire consists of questions about the sociodemographic characteristics, the status of encountering insects and mites, and the sources of information on insects and mites. In addition, the questionnaire included images of insects and mites, 52 propositions to determine the knowledge levels, and questions of known struggling methods.

\subsection{Data Collection}

The study data were collected between October and November 2018. After the approval of the Ethics Committee, the permission of the school administration was obtained. Prior to the application of the questionnaire, the students were informed and the questionnaire was applied to the volunteers. The questionnaires were applied to the students face to face in the classroom environment. The application took approximately 20-25 minutes.

\subsection{Data Analysis}

Data were analyzed using SPSS Version 21.0 (IBM, Armonk, NY, USA). Data were summarized as mean \pm standard deviation and percentage. Chi-square test was employed for the comparison of categorical data. To compare between the two groups, independent t test was used. The level of significance was taken as 0.05 .

\subsection{Ethical Considerations}

For this study, permission was obtained from the Ethics Committee of Nigde Omer Halisdemir University (2018/1106). After the students were informed about the purpose of the research and the questionnaire, the questionnaire was applied to those who gave written and oral consent.

\section{RESULTS}

\subsection{Demographic Information}

The number of female students who participated in the study was $242(86.1 \%)$ and the number of male students was $39(13.9 \%)$. The mean age was $20.09 \pm 1.76$ years. Of the participants, $62.3 \%$ were studying in the nursing department and $37.7 \%$ were studying in the midwifery department. Of the participants, $55.5 \%$ were 1 st-graders and $44.5 \%$ were 4th-graders. $77.6 \%$ of the students were living in dormitories and $15.3 \%$ were living with their families. Of the students, $55.2 \%$ stated that they lived in the province before they started university, $29.2 \%$ in the district, and $10.3 \%$ in the village (Table 1 ). 
Table 1. Sociodemographic characteristics of students

\begin{tabular}{|l|c|c|}
\hline Sociodemographic Characteristics & Number & $\%$ \\
\hline Age & & 56.9 \\
21 years and over & 160 & 43.1 \\
\hline Sex & 121 & \\
Female & & 86.1 \\
Male & 242 & 13.9 \\
\hline Department & 39 & \\
Nursing & & 62.3 \\
Midwifery & 175 & 37.7 \\
\hline Class & 106 & 55.5 \\
1st-grade & 156 & 45.5 \\
4th-grade & 125 & 15.3 \\
\hline Place of residence & & 77.6 \\
At home with family & 218 & 5.3 \\
Dormitory & 15 & 1.1 \\
At home with friends & 3 & 0.7 \\
Alone & 29 & \\
Other & 155 & 55.2 \\
\hline Former living place & & 29.2 \\
Province & & \\
District & & \\
Small town & & \\
Village & & \\
Other & & \\
\hline
\end{tabular}

\subsection{Evaluation of Participants' Statuses Related to Insects and Mites According to Some of Their Characteristics}

The ratio of the participants who had fed an animal once in their lifetime was $54.8 \%$. $63 \%$ of the animal feeders had fed two or more species of animals. The participants stated that they had fed many animals such as cat, dog, bird, fish, chick, cow. The ratio of those engaged in livestock farming was $14.9 \% .50 \%$ of those engaged in livestock farming stated that were engaged in bovine breeding. 52.3\% of the participants answered "yes" and $47.7 \%$ answered "no/no idea" to the question "Have you received information about insects and mites during your education?".

The students stated that they mostly encountered cockroaches (77.9\%), lice (56.2\%) and fleas (41.3) in their daily lives. The students mostly encountered lice (52.5\%) on their bodies. They stated that they would mostly recognize cockroaches (59.7\%) when they saw one (Table 2 ).
There was a significant difference between those who lived in a province and those who lived in other settlements in terms of encountering lice and fleas. According to this, people who lived in settlements such as districts, villages, and small towns encountered lice $(\chi 2=9.132, p=0.03)$ and fleas $(\chi 2=8.885$, $p=0.03$ ) more than those who lived in a province.

There was a significant difference between animal feeders and those who had never feed an animal in terms of encountering lice and ticks. According to this, animal feeders encountered lice $\left(\chi^{2}=4.128, p=0.04\right)$ and ticks $(\chi 2=4.803$, $p=0.02$ ) more compared to those who had never feed an animal. In addition, those who were engaged in livestock farming encountered scabies $\left(\chi^{2}=5.929, p=0.01\right)$ and cockroaches $\left(\chi^{2}=7.380, p=0.00\right)$ more.

In terms of sex, there was a significant difference between female and male students in terms of encountering lice and bedbugs. According to this, female students encountered lice $\left(\chi^{2}=7.605, p=0.006\right)$ more, while male students encountered bedbugs $\left(\chi^{2}=5.212, p=0.02\right)$ more.

Of the participants, $55.2 \%$ stated that they had sufficient information about lice, 35.9\% about fleas, 55.2\% about ticks, $13.5 \%$ about scabies, $50.5 \%$ about cockroaches, and $11.0 \%$ about bedbugs. The source of information was close environment $(54.1 \%)$, courses $(34.8 \%)$ and personal experiences $(40.0 \%)$ for lice; close environment (55.4\%), related courses (36.6\%) and personal experiences $(24.7 \%)$ for fleas; close environment, related press such as TV, newspaper and courses (41.3\%), internet $(40.0 \%)$ and books (13.5\%) for ticks; related courses (55.2\%), internet, close environment (36.8\%) and related press such as TV, newspaper (29.0\%) for scabies; close environment (56.3\%), personal experiences (46.4\%) and internet (13.9\%) for cockroaches; and personal experiences $(46.4 \%)$, internet $(25.8 \%)$ and related courses (19.3\%) for bedbugs.

The ratio of recognizing insects/mites given in images was $34.8 \%$ for lice, $65.1 \%$ for cockroaches, $29.1 \%$ for fleas, $59.4 \%$ for ticks, and $16.4 \%$ for bedbugs.

\subsection{Evaluation of Participants' Knowledge Levels on Insects and Mites According to Their Status of Encountering and Educational Status}

The students were given propositions about the insects/ mites such as their appearances, characteristics, diseases

Table 2. The Ratio of encountering insects and mites in daily life

\begin{tabular}{|c|c|c|c|c|c|c|c|c|c|c|c|c|}
\hline \multirow{4}{*}{ Insects and Mites } & \multirow{2}{*}{\multicolumn{4}{|c|}{ Status of Encountering }} & \multirow{2}{*}{\multicolumn{2}{|c|}{$\begin{array}{c}\text { I saw on my body/in my } \\
\text { environment } *\end{array}$}} & \multirow{3}{*}{\multicolumn{2}{|c|}{$\begin{array}{l}\text { I saw on somebody } \\
\text { else's body/in another } \\
\text { environment* }\end{array}$}} & \multicolumn{2}{|c|}{ I can recognize } & \multicolumn{2}{|c|}{ I cannot recognize } \\
\hline & & & & & & & & & \multirow[t]{3}{*}{$\mathrm{N}$} & \multirow[t]{3}{*}{$\%$} & \multirow[t]{3}{*}{$\mathrm{N}$} & \multirow[t]{3}{*}{$\%$} \\
\hline & \multicolumn{2}{|c|}{ Yes } & \multicolumn{2}{|c|}{ No } & \multirow[t]{2}{*}{$\mathrm{N}$} & \multirow[t]{2}{*}{$\%$} & & & & & & \\
\hline & $\mathrm{N}$ & $\%$ & $\mathrm{~N}$ & $\%$ & & & N & $\%$ & & & & \\
\hline Lice & 158 & 56.2 & 123 & 43.8 & 83 & 52.5 & 93 & 58.9 & 108 & 38.4 & 173 & 61.6 \\
\hline Fleas & 116 & 41.3 & 165 & 58.7 & 37 & 31.9 & 87 & 75.0 & 83 & 29.5 & 198 & 70.5 \\
\hline Ticks & 92 & 32.7 & 191 & 67.3 & 16 & 17.3 & 87 & 94.5 & 97 & 34.5 & 184 & 65.5 \\
\hline Scabies & 13 & 4.6 & 268 & 95.4 & 1 & 7.7 & 12 & 92.3 & 6 & 2.1 & 275 & 97.9 \\
\hline Cockroaches & 219 & 77.9 & 62 & 22.1 & 93 & 42.5 & 149 & 64.8 & 168 & 59.7 & 113 & 40.3 \\
\hline Bedbugs & 50 & 17.8 & 231 & 82.2 & 20 & 40.0 & 36 & 72.0 & 27 & 9.6 & 254 & 90.4 \\
\hline
\end{tabular}

* Multiple options were selected. 
they carry, and struggling methods and they were asked to answer them as true/false/I do not know. The answer "true" was evaluated as " 1 point" and the answers "false" and "I do not know" were evaluated as "0 points". The mean scores of "true" answers given by the students to the propositions on insects and mites were given in Table 3. Accordingly, the most correct answers given to the propositions were about lice. The second most correct answers were given about ticks. The lowest score was obtained about bedbugs.

Table 3. Mean knowledge scores of students on insects and mites \begin{tabular}{|l|l|l|l|l}
\hline Insect/ Mite & Number of Students (N) & Max Score & Mean \pm SD & $\%$
\end{tabular}

\begin{tabular}{|l|c|c|c|c|}
\hline Lice & 281 & 13.0 & $8.03 \pm 2.54$ & 61.8 \\
\hline Fleas & 281 & 6.0 & $2.97 \pm 1.46$ & 49.5 \\
\hline Scabies & 281 & 8.0 & $3.66 \pm 2.55$ & 45.7 \\
\hline Ticks & 281 & 10.0 & $5.80 \pm 2.43$ & 58.0 \\
\hline Bedbugs & 281 & 7.0 & $2.59 \pm 2.18$ & 37.0 \\
\hline Cockroaches & 281 & 8.0 & $3.76 \pm 2.20$ & 47.0 \\
\hline
\end{tabular}

No significant difference was found between midwifery and nursing departments in terms of knowledge scores on insects and mites.

Animal feeders had a higher knowledge level on lice $\left(\chi^{2}=8.519\right.$, $p=0.000)$, ticks $\left(\chi^{2}=6.071, p=0.04\right)$, and cockroaches $\left(\chi^{2}=4.006\right.$, $p=0.04)$. Knowledge score about lice was higher in those who were engaged in livestock farming $\left(\chi^{2}=8.857, p=0.02\right)$.

Knowledge scores according to the status of encountering insects and mites were given in Table 4. Except for scabies, those who encountered insects and mites in their daily lives had higher scores than those who did not.

Table 4. Mean knowledge scores of students according to their statuses of encountering insects and mites

\begin{tabular}{|c|c|c|c|c|c|c|}
\hline Insect/ Mite & Encounter & $\mathbf{N}$ & $x$ & SD & $t$ & $\mathbf{P}$ \\
\hline \multirow{2}{*}{ Lice } & Yes & 158 & 8.49 & 2.35 & \multirow{2}{*}{-3.514} & \multirow{2}{*}{0.001} \\
\hline & No & 123 & 7.43 & 2.67 & & \\
\hline \multirow{2}{*}{ Fleas } & Yes & 116 & 3.25 & 1.39 & \multirow{2}{*}{-2.731} & \multirow{2}{*}{0.007} \\
\hline & No & 165 & 2.77 & 1.48 & & \\
\hline \multirow{2}{*}{ Scabies } & Yes & 13 & 4.69 & 2.32 & \multirow{2}{*}{-1.483} & \multirow{2}{*}{0.139} \\
\hline & No & 268 & 3.61 & 2.55 & & \\
\hline \multirow{2}{*}{ Ticks } & Yes & 92 & 6.36 & 2.26 & \multirow{2}{*}{-2.727} & \multirow{2}{*}{0.007} \\
\hline & No & 189 & 5.53 & 2.47 & & \\
\hline \multirow{2}{*}{ Bedbugs } & Yes & 50 & 4.04 & 1.85 & \multirow{2}{*}{-5.928} & \multirow{2}{*}{$<0.001$} \\
\hline & No & 231 & 2.27 & 2.13 & & \\
\hline \multirow{2}{*}{ Cockroaches } & Yes & 217 & 4.07 & 2.06 & \multirow{2}{*}{-4.336} & \multirow{2}{*}{$<0.001$} \\
\hline & No & 64 & 2.65 & 2.31 & & \\
\hline
\end{tabular}

When the first-graders and fourth-graders were compared in terms of mean knowledge scores on insects and mites, fourth-graders were found to have higher knowledge scores on lice $\left(\chi^{2}=9.240, p=0.00\right)$, fleas $\left(\chi^{2}=3.216, p=0.01\right)$, scabies $\left(\chi^{2}=4.488, p=0.00\right)$, ticks $\left(\chi^{2}=6.208, p=0.01\right)$. The students who received training on insects and mites during their education had higher knowledge scores on insects and mites than those who did not receive (Table 5).
Tablo 5. Mean knowledge scores of students according to their statuses of receiving training on insects and mites

\begin{tabular}{|c|c|c|c|c|c|c|}
\hline Insect/ Mite & Training & $\mathbf{N}$ & $x$ & SD & $t$ & $P$ \\
\hline \multirow{2}{*}{ Lice } & Yes & 147 & 8.87 & 2.56 & \multirow{2}{*}{-6.257} & \multirow{2}{*}{$<0.001$} \\
\hline & No & 134 & 7.10 & 2.18 & & \\
\hline \multirow{2}{*}{ Fleas } & Yes & 146 & 3.38 & 1.46 & \multirow{2}{*}{-5.063} & \multirow{2}{*}{$<0.001$} \\
\hline & No & 135 & 2.93 & 1.33 & & \\
\hline \multirow{2}{*}{ Scabies } & Yes & 146 & 4.33 & 2.61 & \multirow{2}{*}{-4.787} & \multirow{2}{*}{$<0.001$} \\
\hline & No & 135 & 2.93 & 2.26 & & \\
\hline \multirow{2}{*}{ Ticks } & Yes & 146 & 6.68 & 2.15 & \multirow{2}{*}{-6.763} & \multirow{2}{*}{$<0.001$} \\
\hline & No & 135 & 4.84 & 2.36 & & \\
\hline \multirow{2}{*}{ Bedbugs } & Yes & 146 & 3.30 & 2.16 & \multirow{2}{*}{-5.995} & \multirow{2}{*}{$<0.001$} \\
\hline & No & 135 & 1.82 & 1.94 & & \\
\hline \multirow{2}{*}{ Cockroaches } & Yes & 146 & 4.30 & 2.09 & \multirow{2}{*}{-4.403} & \multirow{2}{*}{$<0.001$} \\
\hline & No & 135 & 3.17 & 2.16 & & \\
\hline
\end{tabular}

The ratio of known struggling methods for insects and mites was $72.2 \%$ for lice. $6.5 \%$ of the answers were common struggling methods such as gas oil, vinegar, garlic, and aspirin.

The ratio of known struggling methods for fleas was $37.4 \%$ and $2.9 \%$ of those were common methods such as diesel oil and vinegar. The ratio of known struggling methods for ticks was $40.9 \%$ and $19.3 \%$ of the respondents stated that when encountered a tick, the one should apply to a health care facility and $14.5 \%$ stated personal protective measures such as wearing long clothes in green areas. $4.8 \%$ of the respondents gave incorrect answers such as removing the tick with tweezers, burning, using bleach. The ratio of known struggling methods was $18.1 \%$ for scabies, $41.3 \%$ for cockroaches, and $23.8 \%$ for bedbugs.

\section{DISCUSSION}

This study aimed to determine the knowledge and experiences of students, who were health personnel candidates, on lice, fleas, scabies, ticks, bedbugs, and cockroaches that they may frequently encounter in the field. Because vector-borne diseases cause significant morbidity and mortality worldwide (13). In recent years, there has been a striking change in the geographical and host areas and diseases of many vector-borne pathogens, generally due to climate change and destruction of wild habitats (12). This means that the geographical spread of mites and insects is expanding, and their life cycle processes are changing. Thus, the incidence of vector-transmitted diseases may increase due to their large scale spread.

With the health reform that started in 2003 in Turkey, the family practice system has been realized and spread all over the country by 2010 . With the family practice system, midwives and nurses take an important role in the functioning of the primary health care system together with family physicians (22). Nurses and midwives can consult all individuals, families, and community who are in need in terms of health whether they are sick or healthy at any level of age (23). Consultancy of health personnel becomes more important, especially in rural areas. In this study, those who lived in rural areas and those who were engaged in livestock 
farming encountered insects and mites more. From this point, it becomes more important for health personnel to have knowledge about infections that can be encountered frequently in rural areas and that are caused by insects and mites and diagnosis, treatment and prevention methods. Otherwise, health professionals who are unaware of the presence of these infections generally postpone the diagnosis and treatment and therefore these infections are often ignored when determining the cause of a patient's disease (12). Similar to the other studies conducted in Turkey, female students in this study encountered lice more and the most encountered insect on students' bodies was lice (24). Lice are ectoparasites, can be transmitted by direct human-to-human contact, and can easily cause epidemics. Pediculosis is an important health problem for primary school-age children in Turkey and in many parts of the world, including developed countries (25). Although lice infestation is less common in Turkey, it is still confronted today (26). The studies conducted on lice in Turkey are generally the review articles and focus on prevalence (24). In order to prevent lice infestations, it is recommended to make screenings at regular intervals (27). However, there is no study found describing the knowledge level of health personnel on lice. Therefore, similar studies to be conducted with health personnel are required.

In this study, participants stated that the least encountered one was scabies. Only one female student reported that she had scabies. Similarly, there are a limited number of studies on scabies that determine its prevalence in Turkey (26). The prevalence of scabies worldwide is unknown (28).

Studies conducted on fleas in Turkey mostly include animals (29). Likewise, studies on fleas in the world have been generally conducted on animals $(30 ; 31)$.

The lowest knowledge score of the participants was on bedbugs. In a similar study, it was found that $70 \%$ of people who live at homes where there was bedbug infestation were unaware of the presence of bedbug (32).There are few studies conducted in Turkey on bed bug (Cimex lectularius) (33).

The participants encountered cockroaches the most in their daily lives $(77.9 \%)$ and stated that they would recognize cockroaches the most when they saw one. Likewise, in the studies conducted in the world, participants stated that they encountered cockroaches in their houses ranging from $50 \%$ to $81.5 \%(34,35)$. Studies in Turkey mostly focuses on the allergenic aspect of cockroaches (36).

The importance of ticks has increased in Turkey, especially with the detection of cases of Crimean-Congo Hemorrhagic Fever. In Turkey, especially since 2006, there been an obvious increase in the number of cases, almost $5 \%$ of the cases were fatal (37). This situation has caused the printed and visual media and the Ministry of Health to focus more on the issue. In our study, the students stated that they had the highest knowledge level on ticks as well as lice. Similarly, the sources that students learn about ticks the most are the press such as television and newspapers and the close environment.
Participants' sources of information about insects and mites were generally the experiences they gained by themselves or from their close environment and the training they received.

It is crucial for healthcare professional candidates to properly know medical methods in the struggle against insects and mites. In the struggle against pediculosis it is of particular importance to do checking regularly, obey the personal hygiene rules, change clothes and bedclothes regularly and use products such as shampoo, lotion and cream against pediculosis (38). In the struggle against pediculosis our study also gave traditional, and mis known answers like gas oil, vinegar, garlic, and aspirin use. Scabies is an easily transmitted illness, and it spreads quickly in bad hygiene conditions and crowded spaces. In the struggle against scabies, it is of prime importance to know the symptoms properly, make true diagnosis and treat the patient and his/her relatives. The patient's clothes and bedclothes should be washed properly (17). In the struggle against flea, it is of prime importance to vacuum the environment properly, have the pets checked, cleaned, and treated regularly and wash the patient's clothes (39). In the struggle against flea our study also gave traditional, and mis known answers like diesel and vinegar. In the struggle against bedbugs appropriate insecticides should be applied for beds and floorings (40). The use of chemical insecticides in the struggle against cockroaches has not been chosen in recent years because of their harm to the environment, humans and other creatures and the resistance of the insects (41). Instead, boric acid and insecticidecontaining jelly feed have been used in recent years (42). Also, the use of entomopathogen isolate against cockroaches is becoming widespread (43). In the struggle against ticks the people who live in endemic areas or travel to these areas should pay a particular attention to personal protection. Ticks are usually active between October-April. People should take precautions such as keeping away from areas like grasslands, waterfronts, forests, animal shelters or wearing long-sleeve and light-colored clothes, socks, gumboots and putting the trotters into the socks (44). It is necessary to often check the body and clothes for ticks and immediately remove the tick using fine-tipped pliers or tweezers near the mouth area in an upward position without breaking off and crushing the head or apply to the nearest healthcare organization. Bugrepellents should be used against tick attacks. It is of particular importance to disinfect animal shelters with acaricides and calcimine them with lime (45). In the struggle against ticks our study gave traditional and misknown answers like burning, using bleacher and removing the tick via hands or tweezers without paying attention to its integrity. Fact that the medical personnel candidates also mentioned traditional and misknown methods regarding the methods of struggle against bugs and mites, demonstrates that experiences also play an important part in learning and unless supported with education they may lead to incorrect and/or inadequate learning. The fact that the ratio of those who thought that they had sufficient information about insects/mites and the ratio of recognizing insects/mites given in images were low supports this situation. Likewise, the mean scores of 
participants for propositions about insects and mites were low. In this study, the prominent finding was that knowledge of insects and mites was obtained through experiences and training. It cannot be expected that students have experience for each insect/mite, but they can be taught through courses. In relevant courses, they should be provided real insects and mites, and students should be given the opportunity to examine insects and mites. For this purpose, laboratory practices should be provided with the courses and students should also be allowed to do an internship in rural areas. Because even if students encounter insects and mites in their daily lives, their knowledge will remain insufficient unless supported by theoretical knowledge.

Considering the rapid increase and aging of information, which is the characteristic feature of the information age, nowadays, professional midwifery/nursing education should have the characteristics in a way that it can provide continuous development and adaptation to innovations through effective learning. This necessitates the selection of effective learning methods that will enable learning through experiences in the teaching-learning environment (46).

\section{Strengths and Limitations}

The strength of this study is that it is the first comprehensive study that determines the knowledge levels of students, who will be health personnel in Turkey, on commonly encountered insects and mites. The research cannot be generalized since it included only the students of the school of health in a university.

\section{CONCLUSIONS}

Today's changing conditions have increased the risk of confronting epidemics related to insects and mites at any time. It is highly important for health personnel, who are actively involved in epidemics and who consult the community, to receive effective training on insects and mites. Therefore, the curriculum should be reviewed, appropriate laboratory conditions should be established, and students should be ensured to gain experience through internships. There are limited studies on this topic; therefore, further scientific studies are required.

\section{Acknowledgments}

The authors are grateful to all of the subjects for their participation in this study.

\section{REFERENCES}

[1] Lane RP, Crosskey RW. Medical insects and arachnids.1st ed. London: Springer Science \& Business Media; 1993.

[2] Detinova TS. Age structure of insect populations of medical importance. Annu Rev Entomol 1968; 13(1): 427-450.
[3] Gabre RM. Life-Tables of Important Medical Insects. 1925 April 2012. Proceedings XXIV International Congress of Entomology (ICE 2012), Exco Daegu Korea.

[4] Fotedar R, Banerjee Shrınıwas U, Verma A. Cockroaches \{Blattella germanica) as carriers of microorganisms of medical importance in hospitals. Epidemiol Infect 1991; 107:181-187.

[5] Boiocchi F, Davies MP, Hilton AC. An examination of flying Insects in seven hospitals in the United Kingdom and carriage of bacteria by true flies (diptera: calliphoridae, dolichopodidae, fanniidae, muscidae, phoridae, psychodidae, sphaeroceridae). J Med Entomol 2019; 56(6):1684-1697.

[6] Shahraki GH, Parhizkar S, Nejad ARS. Cockroach infestation and factors affecting the estimation of cockroach population in urban communities. International Journal of Zoology 2013; 1-7.

[7] Zarchi AAK, Vatani H. A survey on species and prevalence rate of bacterial agents isolated from cockroaches in three hospitals. Vector Borne Zoonotic Dis 2009; 9(2): 197-200.

[8] Fardisi M, Gondhalekar AD, Ashbrook AR, Scharf ME. Rapid evolutionary responses to insecticide resistance management interventions by the German cockroach (Blattella germanica L). Sci Rep 2019; 9(1): 8292.

[9] Szymanek M, Wojnowska D, Krasowska D. (2009) Pediculosis - still an up-to-date clinical problem Przegl Lek 2009; 66(4): 206-208

[10] Buczek A, Markowska-Gosik D, Widomska D, Kawa IM. Pediculosis capitis among schoolchildren in urban and rural areas of eastern Poland. Eur J Epidemiol 2004; 19(5): 491-495.

[11] Falagas ME, Matthaiou DK, Rafailidis PI, Panos G, Pappas G. Worldwide prevalence of head lice. Emerg Infect Dis 2008; 14(9): 1493-1494.

[12] Bitam I, Dittmar K, Parola P, Whiting MF, Raoult D. Fleas and flea-borne diseases. IJID 2010; 14(8): e667-e676.

[13] Eisen RJ, Gage KL. Transmission of flea-borne zoonotic agents. Annu Rev Entomol 2012; 57: 61-82.

[14] Reinhardt K, Siva-Jothy MT. Biology of the bed bugs (Cimicidae). Annu Rev Entomol 2007; 52: 351-374.

[15] Bai X, Mamidala P, Rajarapu SP, Jones, SC, Mittapalli O. Transcriptomics of the bed bug (Cimex lectularius) PloS One 2011; 6(1): e16336.

[16] Ashcroft R, Seko Y, Chan LF, Dere J, Kim J, McKenzie K. The mental health impact of bed bug infestations: a scoping review. Int J Public Health 2015; 60(7): 827-837.

[17] Centers for Disease Control and Prevention. Scabies. 2017. Available from: URL: https://www.cdc.gov/parasites/scabies/ resources/scabies_fact_sheet.pdf.

[18] De la Fuente J, Estrada-Pena A, Venzal JM, Kocan KM, Sonenshine DE. Overview: ticks as vectors of pathogens that cause disease in humans and animals. Front Biosci 2008; 13(13): 6938-6946.

[19] Mülteciler Dernegi. Number of Syrians in Turkey. Available from: URL: https://multeciler.org.tr/turkiyedeki-suriyelisayisi/ (accessed 24 Agust 2019)

[20] Sezen I, Turan M, Kaya AA. Türkiye'deki Suriyeli Misafirler ve İlişkilendirilen BulaşıCı Hastalıklar (Syrian refugees in Turkey and associated with infectious diseases) GUJHS 2018; 7(4): 119-127. (Turkish)

[21] Aydoğan S, Metintas S. Immigration and the effects on health status in Turkey. ESTUDAM 2017; 2(2): 37-45 (Turkish). 
[22] T.C. Ministry of Health. Turkey Health Transformation Program Evaluation Report (2003-2011). Ankara: Sağlık Bakanlığı Yayınları; 2012 (Turkish).

[23] Berragan L. Consultancy in nursing: roles and opportunities. J Clin Nurs 1998; 7(2): 139-143.

[24] Ozkan O, Hamzaoglu O, Yavuz M. The prevalence and management of pediculosis capitis in Turkey: A systematic review. Turkiye Parazitol Derg 2015; 39(2): 135.

[25] Gratz NG, World Health Organization. Human lice: Their prevalence, control and resistance to insecticides: A review; 1985-1997. (No. WHO/CTD/WHOPES/97.8). Geneva: World Health Organization. 1997.

[26] Cetinkaya U, Sahin S, Ulutabanca RO. The epidemiology of scabies and pediculosis in Kayseri Turkiye Parazitol Derg 2018; 42(2): 134-138. (Turkish)

[27] Balcioğlu, iC, Kurt O, Limoncu ME, Ermiş VÖ, Tabak T, Oyur T, Muslu H, Kavur H, Görgün S, Girginkardeşler N, Yereli K, Bilaç C, Özbel Y. Are regular controls conducted in schools adequate in lowering the Incidence of head lice (Pediculus capitis) infestation? Kafkas Univ Vet Fak Derg 2012; 18 (Suppl-A): A:151-A154 (Turkish).

[28] Romani L, Steer AC, Whitfeld MJ, Kaldor JM. Prevalence of scabies and impetigo worldwide: a systematic review Lancet Infect Dis 2015; 15(8): 960-967.

[29] Kandemir C, Taskın T, Kosum N, Cemal UN. Importance of flea infestations and ways of strunggle in small ruminant husbandry. J Anim Prod 2019; 60(1): 75-88. (Turkish)

[30] Clark NJ, Seddon JM, Šlapeta J, Wells K. Parasite spread at the domestic animal-wildlife interface: anthropogenic habitat use, phylogeny and body mass drive risk of cat and dog flea (Ctenocephalides spp.) infestation in wild mammals. Parasit \& Vectors 2018; 11(1): 8.

[31] Abdullah S, Helps C, Tasker S, Newbury H, Wall R. Pathogens in fleas collected from cats and dogs: distribution and prevalence in the UK. Parasit \& Vectors 2019; 12(1): 71.

[32] Wang C, Singh N, Cooper R. Field study of the comparative efficacy of three pyrethroid/neonicotinoid mixture products for the control of the common bed bug, Cimex lectularius. Insects 2015; 6(1): 197-205.

[33] Beyhan YE, Mungan M, Babur C. The species of ticks bites on human and their seasonal distribution in Ankara, Turkey. Ankara Üniv Vet Fak Derg 2016; 63:115-119.

[34] Wang C, El-Nour MMA, Bennett GW. Survey of pest infestation, asthma, and allergy in low-income housing. J Community Health 2008; 33(1): 31-39.
[35] Baraki N, Ashenafi W. 3. Cockroaches infestation and awareness of households on their public health importance and associated factors in Harar town. Proceedings of the 33rd Annual Research Review Workshop. In: Frehiwot M, Jemal Y, Mengistu K, Nega A, Admikew H, Kidesena S, Editors. Theme II:Human health, nutrition and welfare; 2016 Apr 21-23; Haramaya University, Ethiopia; pp.29-46.

[36] Yilmaz A, Tuncer A, Sekerel BE, Adalioglu G,Saraclar Y. Cockroach allergy in a group of Turkish children with respiratory allergies. Turk J Pediatr 2004; 46(4):344-349.

[37] Ergönül O. Crimean-Congo hemorrhagic fever (CCHF) in Turkey: a zoonosis which can cause nosocomial infection: invited commentary. Turkiye Klinikleri J Med Sci 2008; 28(5): 677-679.

[38] Centers for Disease Control and Prevention. Parasites-Lice. Available from: URL: https://www.cdc.gov/parasites/lice/ index.html (accessed 20 October 2020)

[39] Centers for Disease Control and Prevention. Fleas. Available from: URL: https://www.cdc.gov/fleas/index.html (accessed 20 October 2020)

[40] Rozendaal JA. Vector control: methods for use by individuals and communities. World Health Organization; 1997. pp.237261. Available from: URL: https://www.who.int/water_ sanitation_health/resources/vector237to261.pdf (accessed 20 October 2020)

[41] Jialin Z, Mingsheng W, JianMing C. Resistance investigation of Blattella germanica to six insecticides and control strategy in Hefei city. Chinise. J. Vector Biology and Control. 2007;18: 9899.

[42] Gore JC, Schal C. Laboratory evaluation of boric acid-sugar solutions as baits for management of German cockroach infestations. J. Econ. Entomol. 2004; 97(2): 581-587.

[43] Erkılıç L, Uygun N. Possibilities of using entomopathogenic fungi in biological control. Turk J Entomol 1993; 17(2), 117128. (Turkish)

[44] World Health Organization. Crimean-Congo haemorrhagic fever. Available from: URL: http://www.who.int/ mediacentre/ factsheets/fs208/en/ (accessed 20 October 2020).

[45] Anderson JF, Magnarelli LA. Biology of ticks. Infect Dis Clin North Am 2008; 22(2), 195-215.

[46] Cavanagh SJ, Hogan K, Ramgopal T. The assessment of student nurse learning styles using the Kolb learning styles inventory. Nurse Educ Today 1995; 15(3): 177-183. 